\title{
Social and philosophical understanding of national and civic identity in the context of interethnic and interreligious conflict risks
}

\author{
Oksana N. Ryabchenko - Alexey I. Prokopyev - Leonid N. Romanchenko - \\ Andrey V. Korzhuev - Julia A. Krokhina
}

DOI: 10.18355/XL.2018.11.02.29

\begin{abstract}
Inter-ethnic and inter-confessional peace is an essential factor for sustainable development, civil society, and preservation of statehood. The most significant challenges we face today, especially the last few years, are closely connected with an acute problem of avoiding ethnic and inter-confessional conflict risks, and erosion of national and civic identity as a result of globalization. Social philosophy approach to the understanding of national and civic identity is important because any identity is a social construct formed in social interaction, and the use of philosophical methods can provide the study involving all factors that influence this phenomenon: political, economic, social, psychological, and others. The purpose of this article is to study possible targets to prevent ethnic and confessional conflict risks and preserve the unique national and civic identity of each nation and each state. Methodological basis for the research comprises philosophical principles, including dialectic synthesis, the transformation of quantity into quality and vice versa, and dialectical contradictions; a philosophical principle of determinism; and a system activity approach. The leading theoretical method to study the problem is a content analysis of scientific papers relevant to the issue under consideration, and factors affecting and contributing to distortion of national and civic identities. The article discusses the definition of identity as the protean term self, self-identity of an individual, a particular group affiliation according to the person's nationality, religion, social status, profession, etc. The inadequate treatment and false interpretation of history, the absence of a national or patriotic idea that is able to unite the people, the insufficient role of the state, and enforcing unconventional views, norms and values have been considered as risks encouraging national and civic identity distortion. The risk of ethnic and religious conflicts occurs when there is a discrepancy between national and civic identities, or their distortion due to economic, political, social crises, or, as it sometimes happens, external influence.
\end{abstract}

Key words: identity, national identity, civic identity, ethnic conflict, religion, confession

\section{Introduction}

Inter-ethnic and inter-confessional peace is an important factor for sustainable development, civil society, and preservation of statehood. The issue has deep historical roots, and indeed constitutes the very nature of many states. Now the modern world is characterized by an acute problem of ethnic and religious conflicts; conflict between religions threatens future of the world. The transition from the concept of globalization that has prevailed for the last 25 years (formation of the European Union) to the concept of the sovereign nation states predominance has occupied the minds for the previous 2 years, especially in 2017. Therefore, it is commonsensical that the problem of understanding of personal identity concept by social philosophers is being discussed from this perspective, i.e. if it should be national (I am a Russian, I am a Tatar, I am a Jew, etc.) or a multinational one (I am Russian, I am American, I am European, etc.).

XLinguae, Volume 11, Issue 2, April 2018, ISSN 1337-8384, eISSN 2453-711X 
Almost stable levels of Russian society in the second decade of the XXI century have raised serious concerns about activity on the whole, the activity of a person involved in new social relationships, in a new economic, political and geopolitical context (Galushkin, 2017a). This, in turn, determines the position of an individual in a society which leads to the development of new types of behavior and new attitudes in a competitive market environment. Today we can say that social, cultural, ethnic and religious conflicts create situations that make us choose specific forms of behavior in society, form our social and national identity and, in the long run, may affect both our further personal development and the society in general (Leonov, 2014).

Issues of national and civic identity are the important issues in social philosophy which are not only of theoretical but also practical importance. Already at the turn of the century, national and religious relations have become a stumbling block in the system of social relations in Russia and throughout the world. Uneven development in the world has led to an increase of mixed-race population when, depending on conditions, language and culture communities or public and social-territorial communities may become actors of national relations. This situation in itself has actualized the ratio of such contradictory phenomena in the contemporary world as 'ethnic - national', 'local-global', 'individual - communal, group', 'civic - cultural' (Medova, 2010; (Galushkin, 2017b).

Modern researchers have stated the importance of social philosophy approach to address not only causes of public crises but ways to resolve them. At this time, the appeal to identity is not just caused by the fact that now we are more than our predecessors interested in who we are. It is highly likely that the modern man feels it much more difficult to answer this question adequately and maintain his identity in his everyday life recognized and appreciated by others (Achkasov, 2012).

E.O. Trufanova (2010) notes that since ancient times, from the works of ancient philosophers, a human has raised the question 'Who am I?'. From a philosophical point of view, it suggests that the main fact here is that the identity is the sequence of both psychological and existential life of a human being. The sense of identity allows us to understand who we are and combine various manifestations of a many-sided personality that arise in the course of one's social interaction with other people in different situations. Human ego and selfhood system combines a huge number of selfimages, each of which representing features of our activities, our behavior, focus in learning activities, features of response and mental reactions in different situations of social interaction. From her point of view, when talking about identity, we need first to talk about identification. Self-identification is the process of the person's determining and building his self. The basis for it may be different - each self-image involves identification taking into account a single basic symptom.

Modern Russian philosophers, scientists, and sociologists present different views on the issue of identity. Thus, V.H. Akayev (2017) wrote that Russia is a real plurality, ethnic, religious and linguistic diversity, and therefore, development of the Russian identity, as well as considering national and civic identity in Russia, is the fundamental task in the consolidation of its multinational population. This is the most important political task for Russia aimed at uniting a multi-ethnic, multi-religious society. Russian national and civic identity is a more inclusive type of identity than ethnic identity and has a predominantly expressed political and cultural meaning.

S.M. Ahmedjanova (2015) also highlights the importance of the development of children's personality and civic identity from their childhood, and she confers it the same status as a national identity. National identity is not similar to the concepts of nationality, although the latter may be factors making the powerful influence on it. National identity is not an inborn trait. It is based on the person's acquired awareness of culture, language and history commonality with a particular group of people. This should be added to his sense of belonging to a specific state, commitment to this state's national identity, national idea and national symbols as the basis of patriotism. 
I.S. Semenko (2009) indicates the relevance of studying national and civil identities as a resource for social development comparing them with the civilization and globalist identities. In the opinion of the author, the need for the earlier values of major national identity features to be revised is linked to the increased risks and hazards caused by the rapid development accompanied by a geopolitical crisis. The return of the state is considered as a redistribution of responsibilities between the actors in the community development. The author also raises questions related to the dialectics of national, civic and civilizational identity and creation, political identity formation, awareness of identity, and the issues of 'compatriot' concept interpretation in modern Russia.

\section{Materials and Methods}

\subsection{General philosophical principles}

In this study, we relied on philosophical principles of development: dialectic synthesis, the transformation of quantity into quality and vice versa, and dialectical contradictions.

\subsection{Philosophical principles}

In our study, we proceeded from the principle of determinism, its essence is the existence of a natural and necessary dependence of the phenomena on the factors generating them. Determinism comes from causality and has the following features:

1) production or origin: the cause produces the effect and not just precedes it;

2) temporary asymmetry: the cause always exists before the effect, and not vice versa;

3) the need, i.e., regardless of the presence in space and time the result inevitably comes: like causes always produce like effects;

4) spatial and temporal continuity, i.e. cause and effect constitute a chain of events in time and space (Alekseev \& Panin, 2003).

\subsection{Theoretical approaches}

We consider the system-activity approach as the main approach to study this problem. In this approach, the activity is considered as a type of active human existence which is primarily focused on creative transformation and understanding of the world around. It is through activities both the human mind and psyche develop and display. In other words, psyche and activities are interrelated and not isolated from each other. Activity has the following characteristics:

1. activity of man is not inherent, it develops during the whole period of socialization (education and training).

2. when carrying out any activity a person is able to go beyond the limits of his/her consciousness, create intellectual, spiritual, and material values, which in turn contributes to historical development and progress of society.

3. activities meet the needs of a person: natural, cultural, cognitive etc.

4. activity is productive; participating in it a person creates new ways that are able to help him meet his needs (Rubinstein, 2012).

\section{Results}

Identity is a property of the human psyche to express in a concentrated form his self, his involvement in various social, state, national, professional, linguistic, political, religious, racial and other groups. National identity is one of the components of one's identity which is associated with the feeling of belonging to a particular nation, country, cultural space (Ahmedjanova, 2015).

The fundamental social function of the social (domestic and civic) identity is associated with involvement in the system of social relationships, the person's desire to belong to communities and groups that will ensure protection of his/her vital interests, basic needs in self-preservation, development and self-expression in the face

XLinguae, Volume 11, Issue 2, April 2018, ISSN 1337-8384, eISSN 2453-711X 
of real or imaginary danger to be infringed on their basic needs by other groups, communities and individual people (Yadov, 1995).

The main mechanism of social identification is to put (or contrast) interests, opinions, values, estimates, patterns of behaviour of one's group (community) in correspondence with those that are supposed, considered, improper, alien (or hostile), or interests that are of no value or controversial to the commonality (Yadov, 1995).

The concept of "identity" has been coined in the scientific lexicon quite recently. It has widely spread in science thanks to the work of E. Erikson (1996), who studies the relationship of social and cultural change and maintenance of ethnic self-identity introduced the term "identity crisis". E. Erikson (1996) spoke of identity as something that is created through transactions between individuals and their social contexts.

Referring to the problem of identity from a philosophical point of view, E.O. Trufanova (2010) suggests that the conditions of the modern society provide an infinite number of possible identities, each of which enables a person to create a certain self-image. As the self-structure becomes complicated, and this complication is in close connection with the fact that identity issue also updates because the more self-images form the more difficult it is to maintain their coherence and consistency, i.e. consider identity with all self-images as a single complex of identity. An adequate identity is a balanced system of self-identity, where all self-images are unmistakably related to each other, and the individual is aware of them all as belonging to him and being a part of his consciousness. Identity crisis manifests itself in the violation of the relations between different self-images; besides, some of the self-images no longer fit into the existing system and require changes and restructuring of identity. However, this complexity at the same time lays the path to the full development of an individual. The self is composed of many self-images, each of which corresponds to one aspect of objective reality and subjective individuality, but only being together and folding individual pictures of the world into a single one they provide integrative view of diverse sources, creates a fully functioning person, an opportunity every time to master a specific aspect of reality from different points of view, thereby creating in their basis the most complete picture of the world. Incapability to multifaceted cognition causes dogmatism and rigidity of thinking. Therefore, it makes sense to speak of the existence of many self-positions that are combined into an aggregate individual experience which make a person's self-identity. Formation of a person's self-identity as a single structure is an active activity carried out by an actor both consciously and unconsciously. Plurality and diversity of self-positions and bringing them together selfhood of a person are of the same importance for understanding and learning. The problem of identity, therefore, becomes a problem of the organization of multifaceted individual experience (Trufanova, 2010).

There are several groups of issues related to social philosophy, the problem of national and civic identity. The first covers issues referring to the genesis of national, civic, new national and state communities formation. The second one involves aspects of national and civic identity evolution under the influence of political, social, cultural and other factors. The third group combines the problems of interrelations and mutual impact of identities and emergence of social myths and prejudices.

A variety of points of view on these issues can be grouped into two large fields. The first is Marxist, suggests that, like all elements of consciousness, national identity has a labile nature and it is a form of realization of various social interests. The content of national consciousness is determined by social relationships that develop in society. Crisis social situation contributes to the revival of the ultra-national ideas struggling for social group rights, competing for property and power. From the point of view of the Marxists, the main idea, in this case, is an uncompromising class struggle; they believed that the role of social is dominant in relation to the national. Modern theoreticians of nationalism, including English, social philosophers, share this approach to some extent. It is permissible to associate extreme forms of national 
identity expression with certain social factors, including new social structure quality of the modern society. One of the sources of nationalism is the competition of urban classes, whereas intellectuals produce the specific forms of national identity embodiment. In other words, the breeding ground for the emergence of national identity is the society stepping away from the traditional settlement to a high level of social mobility (Chernysh, 1995).

Other approaches in social philosophers in line with the neo-Weberian paradigm. They believe that national identity is the product of a New time and a fairly specific situation in the UK. At that time, the traditional English aristocracy, with heavy losses in the Wars of the Roses, with their heavy casualties among the nobility, brought to power new people coming from lower classes. Those who yesterday were the plebeians, artisans, urban riches, sought and established themselves in the role of new elite, on solid ground. This ground translated into reality as a national identity that newly brought upper and lower classes of English society together into a single community. A national identity that was formed then in Britain has remained almost unchanged for all time of the nation's existence. The peculiarity of the Russian national and civic identity is its patrimonialism, or, in other words, close connection with the idea of a strong state and statehood (Chernysh, 1995).

The directions and tendencies in the development exclusively of all the communities that are subjects of public relation are equally determined by the collective identity of their members, that is, a set of ideas that constitute a coherent and consolidated motivation of behavior, both individual and group. A set of beliefs about their place in society, the values and behavioral patterns that are formed on the basis of correlation of a self with significant cultural values in the society, role functions in the social sphere, social institutions and relationships, forms of social and civic identity. 'Large communities', social group, denominations, nations, states (countries), civilization, are considered as the fundamental reference groups for social and civic recognition. A diverse selection of guideline systems (value systems) potentially relevant for the modern human is associated with the development of information society and is the cause for social identity to be fractional with one or another of its components more urgent (Semenko, Lapkin, Pantin, 2010).

Significant changes in social identity and its constituent elements, on the one hand, are the consequence of economic, political, and cultural changes; and on the other hand, cause themselves important social transformations. But in a situation of globalization, the stable basis of national level identification is substituted by all recognizable characters that are a consequence of shared, global space information and communication. The processes of globalization and global expansion of 'information society' are radically changing the agenda in modernization reforms and mechanisms for maintaining identity, thus giving them unprecedented dynamism. Identity crisis is becoming the norm, diversified and depending on how important the civic identity is for a particular community, being, as mentioned above, the basis for political self-determination of a person. The erosion of traditional forms and models of identity reveals different orientations of the identification process. On the one hand, the identification object is associated with cosmopolitan world citizenship. It is based on the norms, rules, and principles of the global market, global financial flows, as well as general behavior models of people involved in such activities. On the other hand, the value of ethnic, religious-sectarian, ethnic, and other 'secondary' identification values increases as certain alternatives and logic for a radical revision of the preexisting national identity foundation focused on the image of the nation-state. Attempts of modern states to fight for the preservation and reproduction of cultural space common to the whole civic nation have encountered resistance of two different vectors of social and cultural development: cultural and informational globalism, unifying identity samples, on the one hand; and the expansion of civil (national)

XLinguae, Volume 11, Issue 2, April 2018, ISSN 1337-8384, eISSN 2453-711X 
cohesion under the pressure of specific claims of ethnic, religious, linguistic, subcultural communities, on the other hand (Semenko, Lapkin, Pantin, 2010).

Studying the problem of identity in a totalitarian society V. A. Yadov (1995) writes that social identity is primarily state-civic identity. In the Soviet society it was expressed as the unconditional demand to recognize official ideology and system of values of the 'Soviet person'; a clear recognition and demonstration of state-approved beliefs, opinions, assessments, ritualized actions of all people's, nationwide, enthusiasm; a huge number of official signs of individual success recognition, specifically by the state and its bureaucratic structures (honors, awards, holidays, certain occupations); and, in the end, the ideology of denouncing 'enemies of the people' and dissidents, i.e. those who do not associate their identity with the ruling elite and, therefore, gets the stamp of an alien element in society. In a democratic society, it is difficult to predict and very ambiguous to interpret the formation of social group identity in such circumstances, even if we have some reliable data about individual elements available. The study of valid and reliable mass data that describes the dominating tendency in social identity formation is considered as relevant information about the formation of social actors under the conditions of radical social and economic transformations. Social identification is a mediator between the influence of a group (community) and social behavior of individuals. Therefore, a fair picture of the trends in the development of social identification at the same time is the basis for more accurate predictions of the mass behavior of different social groups. Social identity processes are the basis for forming more or less stable social interests and mechanisms for developing a civil society. The knowledge about the prevailing trends of social identification will become the basis for predicting a social foundation for various political parties and movements (Yadov, 1995).

L.M. Drobizheva (2008) refers to the study of national civic identity that includes, from her point of view, a loyalty to the state and identification with the citizens of the country, ideas about civic society, responsibility for the fate of the country and the feelings that people experience in this regard (pride, resentment, disappointment, pessimism or enthusiasm). There are cognitive, emotional and regulatory elements (willingness to act in the name of these ideas and experiences) here as well. Ethnic identity, as well as civic, is widely understood, i.e. not only as an identity but also as an opinion, the image of the people, their language, culture, territory, interests, emotional attitudes and, appropriate in some circumstances, the willingness to act on behalf of these images and ideas. In the context of globalization, ethnic identity is often understood as a manifestation of traditionalism, and civic identity is referred to modernity. Being aware that the identity of citizens in Russia is a complex conglomerate of a new Russian identity (nostalgic Soviet, social, regional, local, ethno-cultural, religious), it focuses on the study of positive compatibility of the national civic and ethnic identity, tries to consider the extent of possible dissemination of meanings in civic identity and identification with people of their nationality; understand if national identity is often more positive compared to ethnic and, if so, how they differ in this characteristic; figure out what methods of their compatibility can make a social resource of society; what are the most important social and political contexts can become trigger mechanisms of positive trends in the national civic and ethnic identity (Drobizheva, 2008).

N.A. Galaktionova (2015) studying the problem of identity considered the difference in the interpretation of 'national school' concept in the contemporary and Soviet periods. She says that during the Soviet period the term 'national school' meant a school for small nations, i.e. not related to the Russian nationality, while at present the concept of 'national school' is used to define Russian state-owned, public, school. The author presents a new perspective on the value of the introduction of the Unified State Exam as a unifying factor. She noted the positive role of the Unified State Exam in the formation of a unified educational space of Russia with no ethnic boundaries. The 
author speaks of the need to take into account the international experience in education and carry out adaptation procedures for migrants. She highlights the change of the state policy in the field of migrant education which is reflected in a number of documents, e.g. in the Concept of education development. This will contribute to the formation and development of a unified national and state identity in Russia (Galaktionova, 2015).

E.N. Glagoleva indicates that the main stage of identity formation is the period of youth. She noted that there is currently a crisis of identity among young people. Today, there are two models of identity among the youth in Russian society that depend on living conditions: 'stability model' which is a process of uncertain identity; and 'risk model' with a leading trend to distort legal and patriotic consciousness. This is partly due to the fact that most young people do not have sufficient knowledge about functioning of the major political, state and public institutions, often demonstrate a low level of interest in participation and solution of social tasks, have little interest in history and traditions of their country; their interests are limited to personal problems and interests. Besides, during the last thirty years, a shift in favor of individualistic values and collectivist leveling has become a reality (Glagoleva, 2017).

N.G. Zhukova (2006), considering the issues of globalization in the world community, comes to a conclusion that globalization developing in the modern world covers all areas of social life (economic, political, cultural, etc.) and is a complex and controversial process. On the one hand, it is intrinsic as the integration processes of cultures, civilizations, peoples, and states expand in the process of human development. But, on the other hand, globalization causes loss of national mentality, national identity, national values, and cultures. The world is becoming cosmopolitan and monotonous. Though there are enough opportunities to correct the negative effects of globalization. As people create their history, they can and must eliminate the negative effects of globalization. It is possible and necessary to preserve national identity and national culture.

When studying the problem associated with the possibility of interethnic and interreligious conflicts it is important to understand the peculiarities of civic and ethnic identity formation in a multiethnic and multireligious society. The study of identity essence, its types and functions, structure and conditions of formation, mechanisms of formation is one of the important factors in creating the conditions and prerequisites for adequate formation and development of civic society, formation of a consensus in the society and ensuring interethnic and interfaith understanding as a condition for coexistence of nations and confessions in Russian society.

If we consider the issue of preventing conflicts on ethnic and religious grounds, the process of identity formation appears to be very important. It should be noted that current political processes have raised serious concerns about identity in Russia, the identity formed and developed here due to its poly-nationalism and polyconfessionalism. Recent years characterized by some extent of stabilization and crisis reduction in its social and political system, and it has become possible to rethink the identity and the ratio of its civic and national components adequately. Therefore today, a scientific and pedagogical community is facing the goal to define a new understanding of identity, define the concept of identity and to organize actions for its formation and development (Fakhrutdinov, Mamedlayev, 2013).

\section{Discussions}

Currently, there are two trends distinguished in the development of the world. On the one hand, the idea of globalization, integration of states, their political, economic, social and cultural spheres started thirty years ago is continuing. But at the same time, in the last few years, there has been an evident tendency to shift away from global 
peace and return to individual sovereign states, most often national ones. And one of the reasons is the fear of national and civic identity loss (culture, values, distinctive social and political relations, centuries-old on this or that territory), which was washed away in a global world and replaced by universal values and identity on a 'global minded person'.

Having made a literature review, we came to a conclusion that national and civic identity are multicomponent social constructs emerging in the course of interaction of individuals and social groups. National identity refers to person's awareness of identity to belong to a particular nation, and civic - to regard himself a citizen of a particular state. When they are in harmony and do not contradict each other, the society can develop successfully and be stable. Components of the national and civic identity contribute to making a set of many 'selves' of the person.

A thread of ethnic and religious conflicts occurs when there is a discrepancy between national and civic identities, or their distortion due to economic, political, social crises, or, as it sometimes happens, external influence. When there is an aggravation of 'I am different' structure, a consolidating component is lost; there is a distortion of historical memory, lack of a unifying national idea, patriotism shifts from civic to national imposing, sometimes external, non-traditional worldviews, norms and values which lead to disappearance of stabilizing role of the state.

\section{Conclusion}

Currently, the study of national and civic identity concerning ethnic and religious conflict risks is of significant relevance in connection with the current challenges of human development. In the modern world, the tendency of the crisis of a globalization idea is evident and the need to return to the world of strong, independent states united on a national basis is being discussed in increasing frequency. It is necessary to provide social philosophical understanding of national and civic identity phenomena, as identity is inherently a social phenomenon the formation of which is impossible without social interaction of individuals with small and large social groups and assimilation of social experience, values, norms, worldviews, culture and history in the course of such interaction.

The threat of interethnic and interreligious conflicts that have increased in recent years poses a challenge to study the possible reasons for their occurrence, which will become targets for their prevention, ensure success in preventive measures to minimize the risk of their occurrence. And here one of the possible sources is the deformation of national and civic identity or a mismatch between them.

Philosophical methodology (dialectical method, determinism principle, general logical methods of analysis and synthesis, system-activity approach) will allow us to obtain a deep understanding of the multicomponent constructs, national and civic identity, consider them as constituents, and provide a general understanding of these phenomena.

We agree with the opinion of some researchers that in a broad sense, identity is a concept of self-perception, the person's understanding of his belonging to a particular group of people according to his national, religious, social, professional and other relevant features, and his awareness of this fact (Fakhrutdinov et al., 2014). Formation of identity is possible through the assimilation of one's personal experience, as well as through imposing other people's experiences and assertions (Akayev, 2017). But at the same time, we understand that identity is formed involving a harmonious combination of all of those 'selves' that had formed the personality in the process of socialization and interaction with other people and social groups. National and civic identities are based on those 'selves' that relate to person's awareness and acceptance his belonging to a particular nation and to a particular state. Violation of this harmonious combination leads to a crisis of identity, to its deformation. On a personal level, it could lead to a crisis of identity, psychological problems, endless attempts to find 
'one's self inside oneself' and in society. If we talk about national and civic identity, their deformation, especially at the level of social groups, may cause ethnic and religious conflicts, since it leads to distortion of historical memory, loss of a unifying national idea, patriotism, acceptance of non-traditional worldviews, norms and values, especially under the conditions of no stabilizing role of the state. Ethnic and religious conflicts may also be caused by a mismatch between national and civic identity which can become a trigger, for example, lead to greater separatist sentiments in the region.

Therefore, considering prevention of ethnic and religious conflicts in the aspect of national and civic identity it is important to point out the importance of the state as a solidarity and stability force, which is able to ensure a succession of values, norms and worldviews, as well as a civic society, create and maintain national spirit and national idea from generation to generation.

Materials of the article present theoretical and practical considerations and may be significant and useful for professionals developing programs aimed at preventing the risk of inter-ethnic and inter-confessional conflicts and maintain positive national and civic identity.

Information of the article may be used by for teachers of philosophy, political science, sociology, social psychology; various professionals working on the problem of national-state identity and engaged in the development of programs to prevent ethnic and religious conflict risks; to understand not only instrumental but also the deeper causes for their occurrence. This is due to the fact that nowadays the world population still faces one of the main threats of the emergence of interethnic and interreligious conflicts in multinational and multireligious societies and states.

The problem discussed is one of the most significant issues of our time; that is why peacebuilding has received more considerable attention in recent years. When conducting a research more questions have arisen that need to be solved. It is necessary to continue the research on the interpretation of the national-state identity from the point of view of the social philosophy, continue the study of its deformations and crises both at the theoretical and at the empirical level.

\section{Bibliographic references}

ACHKASOV, V.A. 2012. Ethnic and national identity in the modern world. In: Vestnik of Saint Petersburg University, vol. 6, n. 91, pp. 452-466. ISSN: 1812-9323.

AHMEDJANOVA, S.M. 2015. Formation of national identity. In: A young scientist, n. 14, pp. 438-441. ISSN: 2072-0297.

AKAYEV, V.Kh. 2017. Formation of national identity is the most important factor in the consolidation of the peoples in Russia. Grozny: Publishing house of the Institute for the Development of Education. ISBN - 978-5-98108-028-9.

ALEKSEEV, P.V. - PANIN, A.V. 2003. Philosophy. Moscow: Prospectus publishing house. ISBN 5-98032-164-0.

CHERNYSH, M.F. 1995. National identity: features of evolution. In: Sociological journal, n. 2, pp. 110-113. ISSN: 0132-1625.

DROBIZHEVA, L.M. 2008. National civil and ethnic identity: the problems of positive compatibility. Moscow: Institute of Sociology of the Russian Academy of Sciences. ISBN 978-5-89697-143-6

ERIKSON, E. 1996. Identity: youth and crisis. Moscow: Publishing group "Progress". ISBN 5-01-004479.

FAKHRUTDINOV, R.R. - MAMEDLAYEV, R.Yu. 2013. A phenomenon of identity: civil or ethnic. In: Kazan pedagogical journal, n. 3, pp. 172-181. ISSN 1726$846 \mathrm{X}$.

FAKHRUTDINOV, R.R. - VASINA, V.V. - CHEVERIKIN, E.A. - KHALITOV, R.G. 2014. Social and psychosocial prediction of ethnic and religious conflict risks. 
Kazan: Publishing house of the Academy of social education. ISBN: 978-5-98259060-2.

GALAKTIONOVA, N.A. 2015. Educational strategies of identity formation: nationstate and ethnocultural aspects. Science of Krasnodar, n. 2, 54-73. ISSN 2070-7568.

GALUSHKIN, A.A. 2017a. Operational management of enterprise structures in the sphere of education and science: Problems and methods for their solution. In: European Research Studies Journal, vol. 20, n. 4, pp. 412-420. ISSN: 11082976.

GALUSHKIN, A.A. 2017b. Organizations of the sphere of education and science methods of competitiveness improvement. In: European Research Studies Journal, vol. 20, n. 4B, pp. 421-431. ISSN: 11082976.

GLAGOLEVA, E.N. 2017. National identity formation of modern Russian youth. Available online: http://dogmon.org/formirovanie-nacionalenoj-identichnostisovremennoj-rossijskoj.html

GONDA, D. - EMANOVSKY, P. 2017. The contribution of teaching logic to ethical decision making. In: Communications, vol. 19, n. 1, pp. 126-130. ISSN 1335-4205.

GRECMANOVA, H. - DOPITA, M. - URBANOVSKA, E. . 2017. Ethical aspects of communication in the academic environment. In: Communications, vol. 19, n. 1, pp. 25-29. ISSN 1335-4205.

LEONOV, N.I. 2014. Problem of self-determination in situations of conflict. Problems of risk diagnosis and prevention of inter-ethnic and inter-confessional conflicts. Kazan: publishing house of the Academy of social education. ISBN: 978-598259-059-6.

MEDOVA, Yu.A. 2010. On the relationship between ethnic and social identity. In: Philosophy and society, n. 4, pp. 119-125. ISSN 1681-4339.

Rubinstein, S.L. 2012. The human and the world. Saint Petersburg: Piter. ISBN 9785-459-00888-3.

SEMENKO, I.S. 2009. Dilemmas of national identity: political risks and social acquisition. In: Polis: Political studies, n. 6, pp. 8-23. ISSN: 1026-9487.

SEMENKO, I.S. - LAPKIN, V.V. - PANTIN, V.I. 2010. Identity in the system of coordinates of world development. In: Polis: Political studies, n. 3, pp. 40-59. ISSN: 1026-9487.

TRUFANOVA, Ye. 2010. A person in the maze of identities. In: The problems of philosophy, n. 2, pp. 13-22. ISSN 0042-8744.

YADOV, V.A. 1995. Social and psychological mechanisms of social identity. In: The World of Russia, n. 3, pp. 158-181. ISSN 1811-038X

ZHUKOVA, N.G. 2006. Globalization and preservation of national identity. In: Philosophy and society, n. 2, pp. 146-153. ISSN 1681-4339.

Words: 5986

Characters: 39866 (22,15 standard pages)

Assoc. Prof. Oksana N. Ryabchenko, PhD

Institute of Law, Social Management and Security

Udmurt State University

1 Universitetskaya Str.

426034 Izhevsk

Russia

okt.wa@yandex.ru

Assoc. Prof. Alexey I. Prokopyev, PhD

Department of State and Legal Disciplines,

Plekhanov Russian University of Economics

36 Stremyannyi Pereulok Str.

117997 Moscow 
Russia

alexeyprokopyev@mail.ru

Assoc. Prof. Leonid N. Romanchenko, PhD

Department "life Safety"

Financial University under the Government of the Russian Federation

Leningradsky prospect 49

125993 Moscow

Russia

Lenia@yandex.ru

Prof. Andrey V. Korzhuev, Doctor of Education

Department of Medical and Biological Physics

I M Sechenov First Moscow State Medical University (Sechenov university)

8 Trubetskaya Str.

119991 Moscow

Russia

akorjuev@mail.ru

Prof. Julia A. Krokhina, Doctor of Law,

Department of Legal Disciplines, Higher School of State Audit (Faculty)

Lomonosov Moscow State University

1/13 Vorobyovy Gory

119991 Moscow

Russia

jkrokhina@mail.ru 